\title{
Finite Element Model Updating of a Thin Wall Enclosure under Impact Excitation
}

\author{
O. S. David-west ${ }^{1,}$,, J. Wang ${ }^{2, b}$ and R. Cooper ${ }^{1, c}$ \\ ${ }^{1}$ School of Mechanical and Aerospace Engineering, Ashby Building, Queen's University, Belfast, \\ Northern Ireland, United Kingdom, BT9 5AH \\ ${ }^{2}$ Faculty of Engineering, Kingston University, Friars Avenue, Roehampton Vale London, United \\ Kingdom, SW15 3DW \\ ao.david-west@qub.ac.uk, bJ.Wang@kingston.ac.uk, ${ }^{c}$ r.cooper@qub.ac.uk
}

Keywords: Impact excitation, Model Updating, Frequency Response Function.

\begin{abstract}
Simulation result of a structural dynamics problem is dependent on the techniques used in the finite element model and the major task in model updating is determination of the changes to be made to the numerical model so that dynamic properties are comparable to the experimental result. In this paper, the dynamic analysis of a thin wall structure ( approx. $1.5 \pm 0.1 \mathrm{~mm}$ thick) was realized using the Lanczos tool to extract the modes between 0 and $200 \mathrm{~Hz}$, but the interest was to achieve a good aggreement between the first ten natural frequencies. A shell element with mid size nodes was used to improve the finite element result and the model was tunned using the damping constant, material properties and discretization. The correlation of the results from the impact excitation response test and the finite element was significantly improved. A correlation coefficient of 0.99 was achieved after tunning the model.
\end{abstract}

\section{Introduction}

When numerical or analytical predictions for the dynamic response of a structure are compared with experimental results it is often noticed that there is some degree of mismatch. Due to advances in measurement and analysis techniques experimental measurements with acceptable error is believed to offer more confidence than the finite element model. An acceptable method to resolve this issue is to update the numerical model.

The most important task in model updating is the determination of the changes to be made to the numerical model and hence, maximise the correlation between the numerical and experimental data. D J Ewins [1] has presented some report on this subject and an extensive literature survey on this subject has been reported by Mottershead J E and Friswell M I [2]. J L Zapico et al [3] used a geometric scale of 1:50 to model the response of a bridge under transverse seismic loading; while C Mares et al [4] updated a test structure using the properties of the mode shapes and sensitivity parameters. Michael I Friswell et al [5] have mentioned the use of physical, geometric and generic element parameters and regularization techniques of singular decomposition, L-curves and cross validation for updating. $\mathrm{N} \mathrm{G}$ Nalitolela et al $[6,7]$ adopted the use of mass and/or stiffness addition to update structural parameters.

In most situations there are variables from the test results of similar structures, to get a balance between these uncertainties; C Mares et al [8, 9] and Stefan Reh et al [10] have discussed updating using the stochastic tool of Monte-Carlo analysis. In this report, the numerical result have been improved by the use of discretization, mass and stiffness matrices and the inclusion of average damping constant obtained from experiment. The advances in technology has made enclosures used to reduced noise transferred to the environment in machines such as a generator more complex and hence the need to understand the behaviour precisely. Further studies on this research are tailored towards the development of an updating process for generator canopy using finite element tool. 


\section{Concept of Dynamic Analysis}

The general dynamic analysis will solve the equation of motion which gives the time dependent response of every node point in the structure by including inertial forces and damping forces in the equation.

$$
[M]\{\ddot{x}\}+[C]\{\dot{x}\}+[K]\{x\}=\{F\}
$$

where $[M]$ represents the structural mass matrix, $\{\ddot{x}\}$ the nodal acceleration vector, $[C]$ the structural damping matrix, $\{x\}$ the node velocity vector, $[K]$ the structure stiffness matrix, $\{x\}$ the node displacement vector and $\{F\}$ is the applied time varying load.

In many engineering systems, the natural frequencies and mode shapes of vibration are of interest. However, for vibration modal analysis, the damping is generally ignored and considering a free vibration multi-degree of freedom system, the dynamic equation becomes.

$$
[M]\{\ddot{x}\}+[K]\{x\}=\{0\}
$$

If the displacement vector $\{x\}$, has the form $\{x\}=\{X\} \sin \omega t$, then the acceleration vector is $\{\ddot{x}\}=-\{X\} \omega^{2} \sin \omega t$ and substituting into equation 2, yields the eigenvalue equation.

$$
\left([K]-\omega^{2}[M]\right)\{X\}=\{0\}
$$

Each eigenvalue has a corresponding eigenvector and the eigenvectors cannot be null vectors.

$$
[K]-\omega^{2}[M]=0
$$

Equation [3], represent an eigenvalue problem, where $\omega^{2}$ is the eigenvalue and $\{X\}$ the eigenvector (or the mode shape). The eigenvalue is the square of the natural frequency of the system.

\section{Structure Description and Experimental Procedure}

The thin wall structure used for this study is a box made of steel measuring $900 \times 600 \times 750$ (all in $\mathrm{mm})$. The wall thickness is $1.5 \mathrm{~mm}( \pm 0.1 \mathrm{~mm})$. Fig. 1, is a photograph of the structure and a schematic of the test set-up is shown in Fig. 2. The response vibration measurement of the box under the impact load were obtained under the fixed base boundary condition of the structure. The set up includes a digital Fourier Transfer analysis system having four input channels. The box was excited with an instrumented hammer, as recommended in BS 6897 [11] and the vibration data of the excited structure were acquired via a portable digital laser vibrometer (PDV 100) focused on strategic points on the structure.

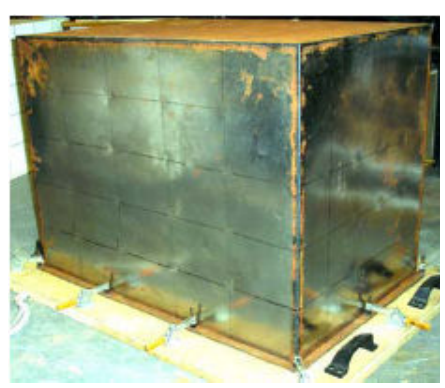

Fig. 1. Photograph of the structure.

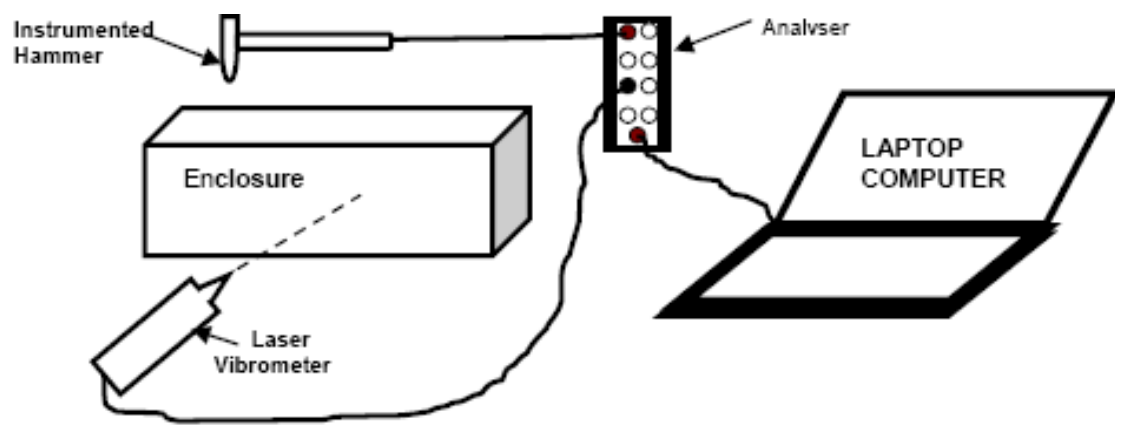

Fig. 2. A schematic of the experimental set-up.

The load and response signals sampled by a Bruel and Kjaer transient analyzer and the frequency response function were visualized via the computer. The test was repeated several times changing the point of input energy; the aim of which is to capture all the modes from the response of the structure. 


\section{Experimental Results}

Fig. 3, shows the overlay of frequency response functions (FRF) of one set of the test and Fig. 4, is the sum of the FRFs.

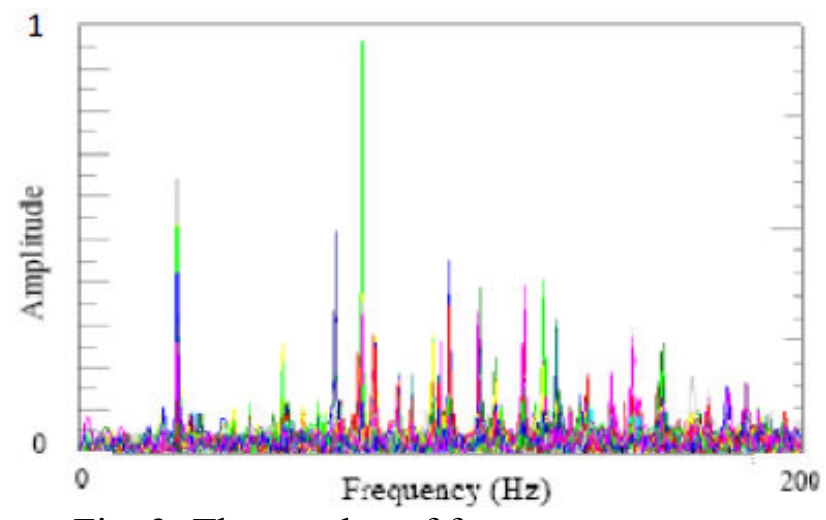

Fig. 3: The overlay of frequency response functions

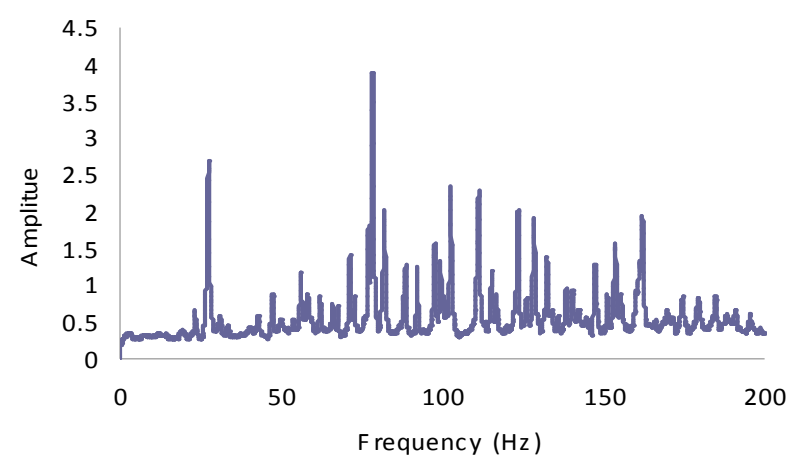

Fig. 4: Sum frequency response function of a test

The dynamic properties of the structure were estimated from the sum frequency response function of every test by the so called peak-picking method. Peak picking is a frequency domainbased technique and a discussion of method is available in reference [12]

\section{Updating Procedure}

After an initial finite element model using ANSYS 11 commercial finite element tool, a sensitivity study was conducted to select the parameters for tuning the model. Fig. 5 is the flow chart illustrating the updating process. In this study we have used the element type, discretization, elastic modulus, average damping constant and material density for updating. The element mass and stiffness matrices is generally presented in the form shown in equations 5 and 6 [13].

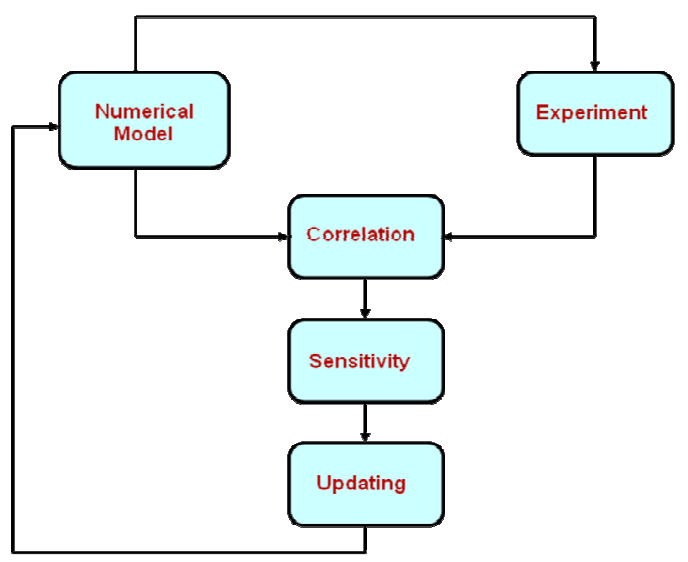

Fig. 5: Schematic of the process of updating

$$
\begin{aligned}
& {[m]=\int_{-1}^{1} \int_{-1}^{1} \int_{-1}^{1} N^{T} \rho N \operatorname{det}(J) d \xi_{1} d \xi_{2} \xi_{3}} \\
& {[k]=\int_{-1}^{1} \int_{-1}^{1} \int_{-1}^{1} B^{T} D B \operatorname{det}(J) d \xi_{1} d \xi_{2} d \xi_{3}}
\end{aligned}
$$


Where $\rho$ is the density, $\mathbf{D}$ the elasticity matrix, $\mathbf{N}$ the matrix of shape functions, $\mathbf{B}$ matrix of shape function derivatives, $\mathbf{J}$ the Jacobian matrix and $\left(\xi_{1}, \xi_{2}, \xi_{3}\right)$ the local co-ordinates. As shown in the above relation, the material density, Young's modulus of the material and the element shape functions affects both the sensitivity and eigendata of a finite element model. The test structure has a thickness of $1.5 \mathrm{~mm}( \pm 0.1 \mathrm{~mm})$ and the measurement points grits of $50 \times 50$ (in $\mathrm{mm})$ were marked on the panels.

Table 1: Natural frequencies

\begin{tabular}{|c|c|c|}
\hline $\begin{array}{c}\text { Experimental } \\
\text { Result }(\mathbf{H z})\end{array}$ & $\begin{array}{c}\text { Result } \\
\text { before } \\
\text { Updating } \\
(\mathbf{H z})\end{array}$ & $\begin{array}{c}\text { Result } \\
\text { after } \\
\text { Updating } \\
(\mathbf{H z})\end{array}$ \\
\hline 16.99 & 15.83 & 17.27 \\
\hline 19.45 & 17.5 & 19.1 \\
\hline 23.47 & 21.36 & 23.31 \\
\hline 26.07 & 23.37 & 25.5 \\
\hline 27.48 & 26.29 & 28.69 \\
\hline 31.63 & 31.01 & 33.83 \\
\hline 33.97 & 32.0 & 34.91 \\
\hline 40.25 & 37.01 & 40.38 \\
\hline 42.55 & 40.17 & 43.83 \\
\hline 46.34 & 42.51 & 46.38 \\
\hline & & \\
\hline
\end{tabular}

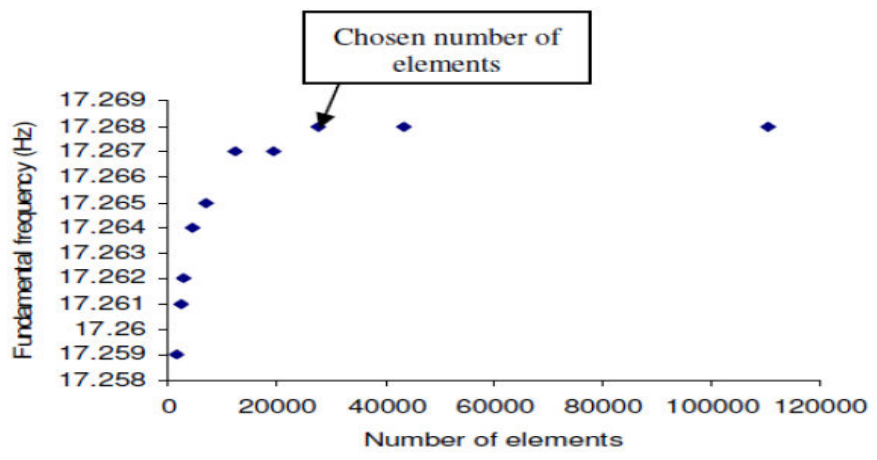

Fig. 6: Identification of convergence.

The initial model was coarse having 6900 elements with element thickness at the lower limit of $1.5 \mathrm{~mm}$. In Table 1 is shown the natural frequencies before and after updating compared to the experimental result. The difference between the frequencies before updating is very high for instance, the fundamental frequency was $15.83 \mathrm{~Hz}$ before updating giving a difference of $1.16 \mathrm{~Hz}$ (ie $0.07 \%$ )in comparison with the experimental result. With improvements obtained the first natural frequencies were $17.27 \mathrm{~Hz}$ from the numerical analysis and $16.99 \mathrm{~Hz}$ from the experiment. This being as expected as with finite element software an ideal fixed boundary condition can be generated. The mass and stiffness matrices were used to improve the finite element result using a shell thickness of $1.6 \mathrm{~mm}$ and elastic modulus of $210 \mathrm{GPa}$ in the stead of $205 \mathrm{GPa}$ used in the initial model. The structure was manufactured with steel procured from Yorkshire steeel company and the elastic modulus as obtained from the site varies from $195 \mathrm{GPa}$ to $225 \mathrm{GPa}$.

The size of the total mass and stiffness matrices of the structure depends on the number of unconstrained nodal degrees of freedom in the model [13]. As the wall thickness of structure is very small it was modelled using a shell element, having mid side nodes in addition to corner nodes, since such elements give better accuracy of the result compared to shell elements with only the corner nodes. The threshold of convergence was as used for the numerical analysis taking cognizance of computational time and accuracy. As shown in Fig. 6, the result converging at the plateau. This being in aggrement with the report of $\mathrm{E} J$ Ewins that its very difficult to update coarse model [1]. The finite element model has 27600 elements.

Table 2: Details of updated model.

\begin{tabular}{|c|c|c|c|c|c|c|}
\hline Element Type & $\begin{array}{c}\text { Number of } \\
\text { Elements }\end{array}$ & $\begin{array}{c}\text { Shell } \\
\text { thickness } \\
(\mathrm{mm})\end{array}$ & $\begin{array}{c}\text { Modulus of } \\
\text { Elasticity } \\
\left(\mathrm{N} / \mathrm{m}^{2}\right)\end{array}$ & $\begin{array}{c}\text { Mass } \\
\text { Density } \\
\left(\mathrm{kgg} \mathrm{mm}^{3}\right)\end{array}$ & $\begin{array}{c}\text { Damping } \\
\text { Constant }\end{array}$ & $\begin{array}{c}\text { Material } \\
\text { Type }\end{array}$ \\
\hline $\begin{array}{c}\text { Shell element } \\
\text { with mid-side } \\
\text { nodes }\end{array}$ & 27600 & 1.6 & $2.1 \mathrm{E}+11$ & 7850 & 0.02 & Steel \\
\hline
\end{tabular}

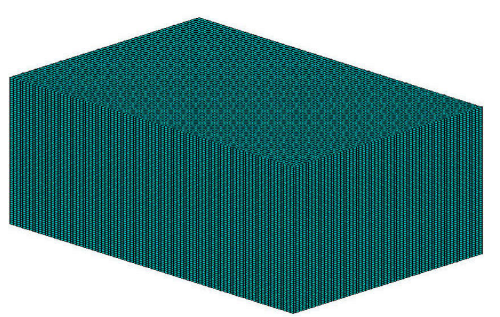

Fig. 7: Finite element discretisation for the enclosure model.

The damping constant or ratio were obtained from the experiment at the resonance peaks of the response function, the value varies from $1.2 \%$ to $2.6 \%$ and an approximate average value of $2 \%$ was 
used for updating (Table 2) as the numerical tool gives the provision for a single value. In a dynamic analysis stiffness distribution is important as well as the mass distribution. The mass matrix [M] can be formulated to be 'consistent' or 'lumped'. The consistent formulation was adopted as it represents better the continuous nature of real structures whereas the lumped formulation is an approximation and save computational time. Fig. 7, shows the finite element discretisation for the box.

\section{Finite Element Results}

The dynamic analysis was realized using the Lanczos tool to extract the modes of the thin walled enclosure between 0 and $200 \mathrm{~Hz}$.

Table 3: Finite element modes of the structure.

\begin{tabular}{|c|c|c|}
\hline $\begin{array}{c}\text { Modes } \\
\text { number }\end{array}$ & Mode shapes & Description of Mode Shape \\
\hline $1,3,5$ & Breathing mode \\
\hline 2 & & $\begin{array}{c}\text { Smaller side panels stationary and breathing at } \\
\text { the top (double breathing) and longer side panels }\end{array}$ \\
\hline $6,7,8$ & $\begin{array}{r}\text { Top and longer side panels, double breathing; } \\
\text { smaller side panels single breathing. }\end{array}$ \\
\hline
\end{tabular}

The fundamental mode is a breathing mode at the natural frequency of $17.27 \mathrm{~Hz}$ and a description of the first eight modes are given in Table 3.

\section{Correlation of Results}

The data for the correlation analysis are the natural frequencies of the box obtained from the excitation response test and the finite element analysis. The relationship is presented in Fig. 8 .

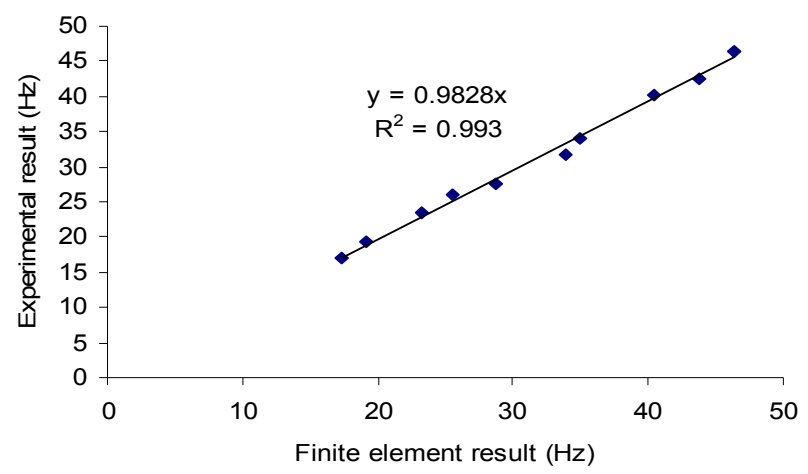

Fig. 8: Correlation of results.

Correlation coefficients is a measure that describe the strength of the relationship between the two quantities. The $R^{2}$ value of 0.99 implies a very good aggrement between the updated numerical result and the experiment. 


\section{Concluding Remarks}

Impact excitation response tests were performed on the thin wall structure. The vibration was generated by the energy input into the structure using an instrumented hammer and the vibration data picked by the use of a laser vibrometer. The dynamic properties of the thin wall structure were estimated from the sum frequency response function of every test by the peak-picking method. The damping constants were obtained from the experiment at the resonance peaks of the response function, the about average value of $2 \%$ was used for updating.

To obtain a numerical solution the structure was discretized with a shell element having mid side nodes and the number of elements in the model was 27600. The results were further updated average damping constant, elastic material modulus and the material density. A satisfactory correletion of approximately one was obtained between the results from experiment and finite element simulation. The fundamental mode of vibration of the structure was breathing.

Enclosure produced by manufacturers for the reduction of noise to the environment in machines such as a generator is becoming more complex using present day technology and hence the need to understand the characteristics of such structures. This study is progressing towards the achievement of an updating tool for generator canopy.

\section{References}

[1] Ewins, D. J. Modal Testing: Theory and Practice Research Studies Press Ltd., 1984.

[2] Mottershead J E and Friswell M I, 'Model Updating in Structural Dynamics: A Survey', Journal of Sound and Vibration (1993) 167(2), 347 - 375.

[3] Zapico, J L, Gonzalez, M P, Friswell, M I, Taylor, C A and Crewe, A J, 'Finite Element Model Updating of a Small Scale Bridge', Journal of Sound and Vibration, 268 (2003) pp 993 - 1012.

[4] Mares C, Mottershead, J E and Friswell M I 'Results Obtained by Minimising Natural Frequency Errors and Using Physical Reasoning' Mechanical Systems and Signal Processing (2003) 17(1) $39-46$.

[5] Friswell, M I; Mottershead J E and Ahmadian, H; 'Finite-element Model Updating using Experimental Test Data: Parametrization and Regularization', Phil. Trans. Royal Society of London A (2001), pp 169 - 186.

[6] Nalitolela, N; Penny, J E T and Friswell, M I; 'Updating Model Parameters by Adding an Imagined Stiffness to the Structure'; Mechanical Systems and Signal Processing (1993) 7(2), pp $161-172$.

[7] Nalitolela, N G; Penny, J E T and Friswell M I; 'Mass or Stiffness addition Technique for Structural Parameter Updating', International Journal of Analytical and Experimental Modal Analysis', vol. 7 no 3, pp 157 - 168, Jul 1992.

[8] Mares, C; Mottershead, J E and Friswell, M I; 'Stochastic Model Updating: Part 1: Theory and Simulated Example', Mechanical Systems and Signal Processing 20 (2006) pp 1674 - 1695.

[9] Mottershead J E, Mares C, James S and Friswell M I; 'Stochastic Model Updating: Part 2: Application to a Set of Physical Structures', Mechanical Systems and Signal Processing 20 (2006) pp $2171-2185$.

[10] Stefan Reh, Jean-Daniel Beley, Siddhartha Mukherjee and Eng Hui Khor; 'Probabilistic Finite Element Analysis using ANSYS', Structural Safety 28 (2006) pp 17 - 43.

[11] B S 6897 Part 5, 1995, 'Experimental Determination of Mechanical Mobility'.

[12] Jimin He and Zhi-Fang Fu: Modal Analysis, $1^{\text {st }}$ ed: Butterworth-Heinemann 2001.

[13] M I Friswell and J E Mottershead 'Finite Element Model Updating in Structural Dynamics' Kluwer Academic Publishers, 1995.

Acknowledgement: Thank to 'Technology Strategy Board' (project number, TP/8/ADM/6/I/Q2017G) and 'EPSRC' (project number DT/F006829/1) for funding this project 